\title{
The Role of Serotonin in the Development of Experimental Diverticulosis
}

\author{
AM Puzikov ${ }^{1}$, GS Mikhailyants ${ }^{2}$ and AE Lychkova ${ }^{1 *}$ \\ ${ }^{1}$ Moscow Health Department, Russia \\ ${ }^{2}$ Surgery department, Russia \\ *Corresponding author: Alla E Lychkova, Head of the Department for Patent and Inventive Work, Russia
}

\begin{abstract}
ARTICLE INFO
Received: 幽 July 02, 2019

Published: 杫 July 10, 2019

Citation: AM Puzikov, GS Mikhailyants, AE Lychkova. The Role of Serotonin

ABSTRACT

Diverticulosis was simulated by creating a local depression in the wall of the intestine of rats by creating a vacuum of $0.1 \mathrm{~atm}$ at the distal portion of the cecum. Studies of the role of serotonin in the development of experimental diverticulosis was carried out by preliminary administration of serotonin at a dose of $100 \mathrm{mg} / \mathrm{kg}$. It was demonstrated that serotonin enhances the contractile activity in experimental colon diverticulosis during the first 10 days from the beginning of simulation and has koloprotective action.
\end{abstract} in the Development of Experimental Diverticulosis. Biomed J Sci \& Tech Res 19(3)-2019. BJSTR. MS.ID.003310.
Keywords: Experimental diverticulosis; Serotonin

\section{Introduction}

In the pathogenesis of diverticular disease (DD) and a number of other intestinal diseases, intestinal innervation disorders are of great importance, accompanied by impaired motor function [1]. These phenomena are based on both a weakening of the inhibitory effects of the cerebral cortex on the lower parts, with a significant decrease in the reactivity of the sympathetic division of the autonomic nervous system and a decrease in the level of neurotransmitter catecholamines, and an increase in the blood content of biologically active substances - serotonin (5-hydroxytryptamine, 5-HT) . Serotonin is an important regulator of intestinal secretion and motility [2-4]. More than 95\% of serotonin is deposited in the intestine, where 5 -HT is synthesized by enterochromaffin (EC) cells. Serotonin-containing cells make up about $70 \%$ of the total endocrine cell population.

Enteroendocrine cells, the ratio of which may vary, contain 5-HT and numerous peptides that regulate the motor, secretory and sensory activity of the intestine in physiological concentrations $[5,6]$. Serotonin is secreted by EC cells of the mucosal lamina in response to mechanical, chemical and other stimuli [2], and the release of 5 -HT is the main trigger of peristalsis, secretion and signaling of visceral sensitivity [7].
Transmission of mucosal serotonin excitation includes the following sequence of events:

a) Stimulation of mucosal cells (for example, acidic, mechanical, or stressful stimuli) triggers the release of 5-HT by cells of the mucosal lamina propria;

b) Activation of 5-HT receptors of adjacent nerve fibers;

c) Removal of 5-HT from the interstitial space using a serotonin transporter (SERT) that expresses any epithelial cells; and

d) Intracellular degradation of serotonin using monoamine oxidase $[2,4,8,9,10]$.

There are different opinions regarding the role of serotonin in the development of motility disorders in diverticular disease (DD). The gene expression profiles of the serotonergic system and the distribution of the 5-HT4 serotonin receptor were studied in a recent study of patients with DD and the role of serotonin and the 5-HT4 receptor in its pathogenesis was recognized [1]. In Costegio M.M. et al. (2008) the effect of serotonin on DM is negated, and emphasis is placed on the role of the serotonin transporter SERT 
in the pathogenesis of diverticular disease [4]. The aim of this study was to clarify the possible pathogenetic role of serotonin in the development of diverticulosis.

\section{Methods of Research}

The experiments were carried out on 22 Wistar rats weighing 260-300 $\mathrm{g}$ in strict accordance with the requirements of the European Convention on the gentle attitude towards experimental animals in conditions of acute experience. Diverticulosis was modeled by creating a local vacuum of 0.1 atm with an area of 1 $\mathrm{mm} 2$ at 5-7 points of the distal cecum. The level of electromotive activity (EMG) was used to determine the hypokinetic and hyperkinetic state of the ileum, the distal blind and the ascending part of the large intestine when simulating diverticulosis and on the 10th day of its development using bipolar surface electrodes with a contact surface area of 1.5-2 mm2. Registration was performed using a Nishon-Konden multichannel polygraph. The study of the role of serotonin was performed in a series of experiments on 10 rats by administering serotonin at a dose of $100 \mu \mathrm{g} / \mathrm{kg}$ for 1-4 minutes before creating a model of diverticulosis. The control group consisted of 5 experimental animals.

Morphological study of the cecum was performed on the 10 th day of the experiment. The tissue was fixed in a $9 \%$ formalin solution, dehydrated in alcohols of increasing concentration. After dehydration, tissue samples were embedded in paraffin, histological sections were prepared. Analysis of changes in the wall Table 1: Experimental diverticulosis with serotonin administration of the cecum was performed on sections stained with hematoxylin and eosin and according to Van Gieson. Statistical processing of the data was performed using the Statistica-17 software package. All quantitative data that obey the normal distribution are presented as $\mathrm{M} \pm \mathrm{m}$. To process the data obtained, the Student criterion ( $\mathrm{t}$ ) was applied, followed by determining the level of significance of differences ( $p$ ) and the criterion $\chi 2$. Differences between mean values were considered significant at $\mathrm{p}<0.05$.

\section{Research Results}

The background EMG of the ileum was characterized by highfrequency ( $15.1 \pm 0.8$ per minute) and low-amplitude $(0.08 \pm 0.001$ $\mathrm{mV}$ ) slow waves. Spike activity was observed in $60.5 \%$ of cases: the frequency of spikes was $0.4 \pm 0.06$, the amplitude $-0.09 \pm 0.0011 \mathrm{mV}$. The background EMG of the cecum was characterized by slow-wave activity with a frequency of $8.0 \pm 0.9$ per minute and an amplitude of $0.12 \pm 0.01 \mathrm{mV}$. In $39.5 \%$ of cases, low-amplitude $(0.03 \pm 0.004$ $\mathrm{mV})$, mid-frequency $(1.1 \pm 0.09)$ spike activity were recorded (Table 1). The background EMG of the ascending part of the colon was characterized by slow-wave activity with a frequency of $9.4 \pm 0.7$ per minute and an amplitude of $0.1 \pm 0.009 \mathrm{mV}$. In $20 \%$ of cases, low-amplitude $(0.06 \pm 0.0015 \mathrm{mV})$, low-frequency $(0.02 \pm 0.0055)$ spike activity were recorded (Table 1 ). Thus, the background motor activity of the ileum and caecum, the ascending part of the colon, was quite intense, since spike activity was noted in a significant percentage of cases.

\begin{tabular}{|c|c|c|c|c|}
\hline \multicolumn{5}{|c|}{ The Intestinal Section } \\
\hline & & Iliac & Blind & Ascending \\
\hline \multirow{4}{*}{ phone } & SW F & $15.1 \pm 0.8$ & $15.1 \pm 0.8$ & $15.1 \pm 0.8$ \\
\hline & SW A & $0.08 \pm 0.001$ & $0.08 \pm 0.001$ & $0.08 \pm 0.001$ \\
\hline & Sp $\quad F$ & $0.4 \pm 0.06$ & $0.4 \pm 0.06$ & $0.4 \pm 0.06$ \\
\hline & Sp A & $0.09 \pm 0.001$ & $0.09 \pm 0.001$ & $0.09 \pm 0.001$ \\
\hline \multirow{4}{*}{$\begin{array}{c}\text { serotonin } \\
\text { administration }\end{array}$} & SW F & & $11.5 \pm 0.9$ & \\
\hline & SW A & $19.2 \pm 1.5$ & $0.18 \pm 0.02$ & $10.5 \pm 0.8$ \\
\hline & Sp $\quad F$ & $0.08 \pm 0.001$ & $0.11 \pm 0.001$ & $0.19 \pm 0.015$ \\
\hline & $\mathrm{Sp} \mathrm{A}$ & & $0.06 \pm 0.001$ & \\
\hline \multirow{4}{*}{\multicolumn{2}{|c|}{ Diverticulosis }} & $11.3 \pm 1.1$ & $11.3 \pm 1.1$ & $9.5 \pm 2.3$ \\
\hline & & $0.16 \pm 0.03$ & $0.16 \pm 0.03$ & $0.06 \pm 0.01$ \\
\hline & & $0.6 \pm 0.02$ & $0.6 \pm 0.02$ & $0.26 \pm 0.09$ \\
\hline & & $0.05 \pm 0.003$ & $0.05 \pm 0.003$ & $0.04 \pm 0.003$ \\
\hline \multirow{4}{*}{\multicolumn{2}{|c|}{ Diverticulosis + serotonin }} & & $11.5 \pm 1.1$ & \multirow{4}{*}{$\begin{array}{c}17.5 \pm 1.3 \\
0.15 \pm 0.01\end{array}$} \\
\hline & & $15.0 \pm 1.0$ & $0.19 \pm 0.012$ & \\
\hline & & $0.1 \pm 0.03$ & $0.7 \pm 0.06$ & \\
\hline & & & $0.04 \pm 0.0011$ & \\
\hline \multirow{4}{*}{\multicolumn{2}{|c|}{ Diverticulosis + serotonin throu 10 days }} & $16.8 \pm 1.3$ & $13.6 \pm 0.7$ & $9.9 \pm 0.7$ \\
\hline & & $0.12 \pm 0.02$ & $0.14 \pm 0.08$ & $0.5 \pm 0.015$ \\
\hline & & $0 / 17 \pm 0.001$ & $2.5 \pm 0.2$ & $0.9 \pm 0.18$ \\
\hline & & $0.05 \pm 0.001$ & $0.05 \pm 0.0012$ & $0.01 \pm 0.0012$ \\
\hline
\end{tabular}

Designations: MW - slow waves, Sp- spike activity, H - frequency, A - amplitude. 
The introduction of serotonin increases the frequency of the slow waves of the EMG of the ileum to $19.2 \pm 1.5$ per minute (by $26.6 \%, \mathrm{p}<0.05$ ), while maintaining the amplitude of the indicators of slow waves. The introduction of serotonin increases the amplitude-frequency characteristics of the EMG slow waves of the caecum: the frequency of the slow waves was $11.5 \pm 0.9$ per minute (by $43.8 \%)$ and the amplitude - up to $0.18 \pm 0.02 \mathrm{mV}(50 \%, \mathrm{p}<0.05)$. Low-frequency $(0.11 \pm 0.001)$ and low-amplitude $(0.06 \pm 0.01212$ $\mathrm{mV}$ ) spike activity is detected (Table 1). Slow-wave activity of the ascending part of the colon with the introduction of serotonin increased: frequency - up to $10.5 \pm 0.8$ per minute $(11.7 \%$, p $<0.05)$, amplitude - up to $0.19 \pm 0.015 \mathrm{mV}(90 \%, \mathrm{p}<0.05)$. The administration of serotonin is characterized by an increase in the indices of slow-wave activity in all the sections of the colon that are examined. At the same time, there is a decrease in the excitability of smooth muscle cells due to a decrease in spike activity in the ileum and the ascending part of the large intestine.

Changes in the motor function of the intestinal sections under study in simulating diverticulosis are presented in Table 1. Serotonin, administered 1-4 minutes prior to modeling of diverticulosis, increases the frequency of the slow waves of the ileum of the ileum to $15.0 \pm 1.0$ per minute $(32.7 \%, p<0.05)$ and its amplitude to $0.10 .03 \mathrm{mV}$ (by $37 \%, \mathrm{p}<0.05$ ), practically returning the slow-wave EMA to the background level. Serotonin, administered 1-4 minutes before the simulation of diverticular disease in the cecum, changes the EMG as follows: slow-wave activity remained stable (frequency - 11.5 \pm 1.1 per minute, amplitude $-0.19 \pm 0.012 \mathrm{mV}$ ); there was a decrease in the frequency of spike activity to $0.7 \pm 0.06$ and a decrease in the amplitude of the spikes to $0.04 \pm 0.0011 \mathrm{mV}$ (Table 1). Serotonin, administered prior to modeling diverticulosis. increases the frequency of slowwave activity of the ascending part of the colon to $17.5 \pm 1.3$ per minute with an increase in the amplitude of $0.15 \pm 0.01 \mathrm{mV}$. That is, the administration of serotonin prior to modeling diverticulosis is characterized by an increase in the frequency of EMG slow waves: an increase in the frequency of slow ileal waves, a stable caecum frequency and an increase in the frequency of EMG slow waves in the ascending colon. Smooth muscle excitability in simulations of diverticulosis is significantly reduced in the cecum and the ascending part of the colon. On the 10th day after the simulation of diverticulosis on the background of prior administration of serotonin, an increase in the amplitude-frequency characteristics of the slow waves of the ileum is observed - frequencies up to 16.8 \pm 1.3 per minute $(12 \%, \mathrm{p}<0.05)$ and amplitude - up to $0.12 \pm 0.02$ $\mathrm{mV}(20 \%, \mathrm{p}<0.05)$, practically exceeding the slow-wave EMG of the background level. There is a tendency to restore spike activity. On the 10th day after the simulation of diverticulosis by serotonin administrated, the cecum is characterized by a further increase in the frequency of slow waves to $13.6 \pm 0.7$ per minute $(18.2 \%$, p $<0.05$ ), a decrease in amplitude exceeding the background level by $16.7 \%$, and a significant increase in the frequency of spike activity to $2.5 \pm 0.2,2.3$ times excess and amplitude of spikes by $66.7 \%$, to $0.05 \pm 0.0012 \mathrm{mV}$ (Table 1).

On the 10th day after the simulation of diverticulosis byserotonin administrated, the ascending part of the colon is characterized by a decrease in the frequency of slow-wave activity to $9.9 \pm 0.7$ per minute $(43.4 \%, \mathrm{p}<0.05)$ with a significant increase in amplitude - 2, 3 times and recovery of spike activity, the frequency of spikes of which exceeds the background level by 2.25 times, but with a decrease in the amplitude of spike activity by 2 times. Thus, 10 days after the simulation of diverticulosis in the presence of serotonin, there is an increase in motor function, especially of the ileum, with a change in the excitability and contractile activity of the ascending part of the colon. A morphological study of the wall of the cecum on the 10th day of development of diverticulosis revealed signs of development of immune reactions: interepithelial lymphocytes were found in the surface epithelium, isolated macrophages and individual plasma cells were found in the subepithelial layer. There is abundant lymphoid cell infiltration of the mucous layer. The number of goblet cells is dramatically increased.

The introduction of serotonin in the simulation of diverticulosis, according to a histological study of drugs of the cecum, is accompanied by a violation of the integrity of the epithelial layer, in which individual MELs are noted. Hyperplasia of colonocytes is noted in some villi (Figure 1a). Infiltration of the mucous membrane by lymphocytes and macrophages and a small number of plasma cells is observed, which reflects a slight decrease in the voltage of the immunological process. A relative decrease in the number of goblet cells at different stages of the secretory process was found (Figure 1b). There is hyperplasia of Pannet cells. Increased proliferative activity of crypt stem cells leads to the formation of clusters of poorly differentiated epithelial cells. Introduction of serotonin, apparently, promotes preferential differentiation of stem cells of crypts into colonocytes, and not into goblet cells.

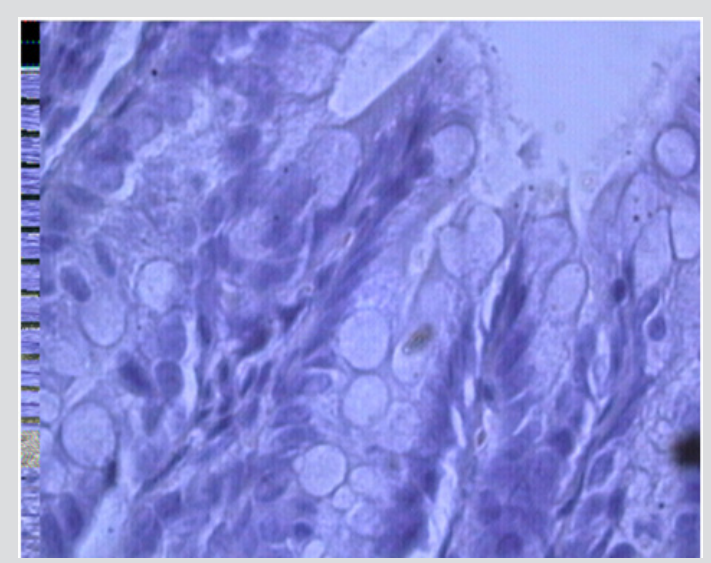

Figure 1a: Violation of the integrity of the epithelial layer and histiocytes, infiltration with lymphocytes and macrophages and individual plasma cells, reflecting the voltage of the immunological process; relative decrease in the number of goblet cells at different stages of the secretory process in case of diverticulosis against serotonin. 


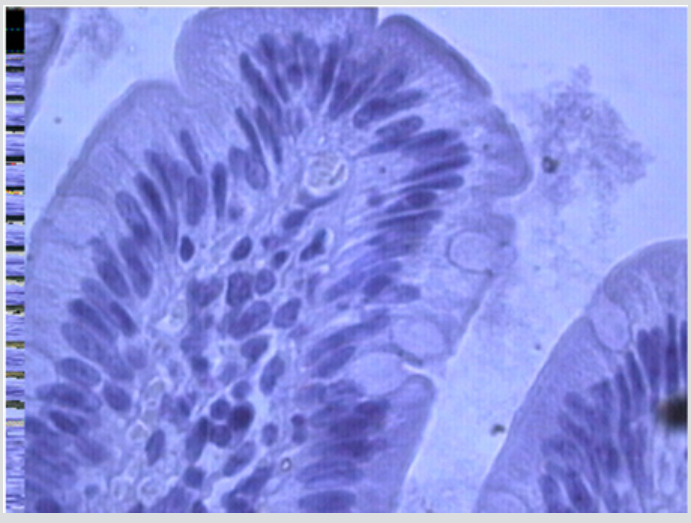

Figure 1b: MEL infiltration, small goblet cells, villous colonocyte hyperplasia with diverticulosis against serotonin.

The development of coarse connective fibers along the vessels in the villi and on the border of the mucous and submucosal layer (Figure 2) is revealed up to the development of tissue hyalinosis along the muscularis mucosa. Separate connective tissue fibers penetrate between muscle fibers and divide them into groups. There is hyperplasia of the submucosal and intermuscular nerve plexus (Figure 3), vacuolar dystrophy of individual neurons, which indicates the imperfection of the nervous regulation of mucus secretion and motor function of the intestine with diverticulosis. So, when simulating diverticulosis, the motor function of all the intestinal sections studied is increased: the ileum and the cecum, and the ascending part of the large intestine. The introduction of serotonin increases, above all, the slow-wave activity of all parts of the intestine, enhancing the propulsion motility. Diverticulosis is characterized by an increase in the slow-wave activity of smooth muscles, primarily of the cecum (zone of formation of diverticula). Simulation of diverticulosis on the background of prior administration of serotonin leads to a significant increase in slow-wave activity above and below the zone of simulation of diverticulosis. On the 10th day after the simulation of diverticulosis against the introduction of serotonin, the motor function of the ileum and the cecum continues to increase with a decrease in the motor function of the ascending part of the large intestine.

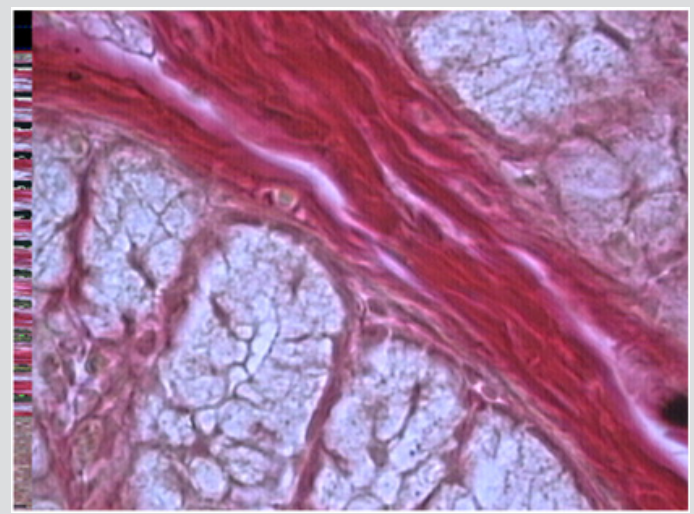

Figure 2: Coarse connective tissue fibers at the border of the mucous and submucosal layer with diverticulosis against serotonin.

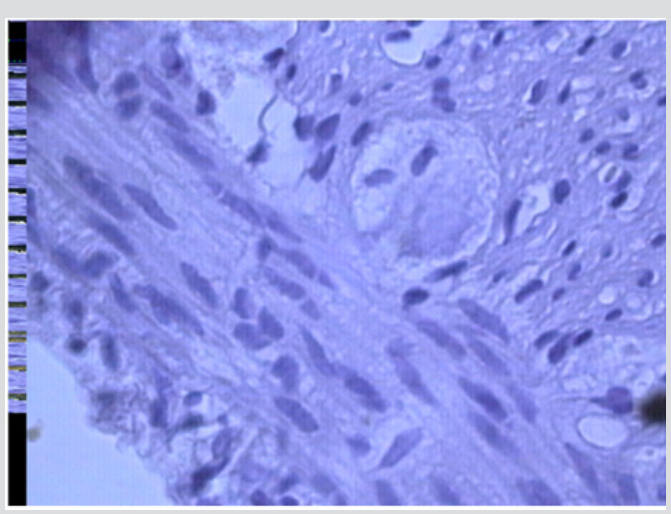

Figure 3: Ganglia of the intermuscular nerve plexus: neurons with signs of vacuolar degeneration, destruction of individual cells during diverticulosis against serotonin..

Preliminary administration of serotonin reduces the manifestations of stress immunological process: reduces the number of MEL, lymphoid-plasmacytic mucosal infiltration; there is an increase in the development of connective tissue up to hyalinosis. These changes indicate that serotonin prevents the development of immune inflammation in case of diverticulosis and transformation of diverticulosis into diverticulitis. It should be noted that the prior introduction of serotonin on the principle of feedback prevents the release of endogenous serotonin, which is characteristic of alteration processes. It is because of the competitive relationship between exogenous and endogenous serotonin as a whole that the damaging effect of the pathogenic factor on the tissue of the cecum decreases (in the case of diverticulosis - negative pressure). It can also be assumed that the decrease in the damaging effects of exogenous serotonin is associated with desensitization of serotonin receptors of the colon under the influence of endogenous serotonin (serotonin nerve endings, platelets, EC cells, mast cells) and exogenous serotonin. Perhaps the role played by the ratio of intracellular and extracellular serotonin [11], which may affect the development of connective tissue. The decrease in the electromotive activity of the colon is an integral indicator of the neurodystrophic process, excessive collagen formation and proliferation of the colon epithelium with the formation of multicellular clusters of undifferentiated epithelial cells.

\section{References}

1. Böttner M, Barrenschee M, Hellwig I, Harde J, Egberts JH, et al. (2013) The enteric serotonergic system is altered in patients with diverticular disease. Gut 62(12): 1753-1762.

2. Gershon MD (1999) Review article: roles played by 5-hydroxytryptamine in the physiology of the bowel. Aliment Pharmacol Ther 13(2): 15-30.

3. Hansen MB (2003) Neurohumoral control of gastrointestinal motility. Physiol Res 52(1): 1-30.

4. Costedio MM, Coates MD, Danielson AB, Buttolph TR 3rd, Blaszyk HJ, et al. (2008) Serotonin signaling in diverticular disease. J Gastrointest Surg 12(8): 1439-1445.

5. Linden DR, Chen JX, Gershon MD, Sharkey KA, Mawe GM (2003) Serotonin availability is increased in mucosa of guinea pigs with TNBS-induced colitis. Am J Physiol Gastrointest Liver Physiol 285(1): G207-G216. 
6. O Hara JR, Ho W, Linden DR, Mawe GM, Sharkey KA (2004) Enteroendocrine cells and 5-HT availability are altered in mucosa of guinea pigs with TNBS ileitis. Am J Physiol Gastrointest Liver Physio 287(5): G998-G1007.

7. Jin JG, Foxx Orenstein AE, Grider JR (1999) Propulsion in guinea pig colon induced by 5- hydroxytryptamine (HT) via 5-HT4 and 5-HT3 receptors. J Pharmacol Exp Ther 288(1): 93-97.

8. Coates MD, Mahoney CR, Linden DR, Sampson JE, Chen J, et al. (2004) Molecular defects in mucosal serotonin content and decreased serotonin reuptake transporter in ulcerative colitis and irritable bowel syndrome. Gastroenterology 126(7): 1657-1664.

ISSN: 2574-1241

DOI: 10.26717/BJSTR.2019.19.003310

Alla E Lychkova. Biomed J Sci \& Tech Res

CC $(P)$ This work is licensed under Creative

Submission Link: https://biomedres.us/submit-manuscript.php
9. Gershon MD (2004) Review article: serotonin receptors and transporters -- roles in normal and abnormal gastrointestinal motility. Aliment Pharmacol Ther 20(7): 3-14.

10. Grider JR, Foxx Orenstein AE, Jin JG (1998) 5-Hydroxytryptamine4 receptor agonists initiate the peristaltic reflex in human, rat, and guinea pig intestine. Gastroenterology 115(2): 370-380.

11. Pavone LM, Norris RA (2013) Distinct signaling pathways activated by "extracellular" and "intracellular" serotonin in heart valve development and disease. Cell Biochem Biophys 67(3): 819-828.

$\begin{array}{ll}\text { BIOMEDICAL } & \text { Assets of Publishing with us } \\ \text { RESEARCHES } & \text { - Global archiving of articles } \\ & \text { - Immediate, unrestricted online access } \\ & \text { - Rigorous Peer Review Process } \\ \end{array}$

